\title{
Structural and Electrical Properties of Li-Ni Nanoferrites Synthesised by Citrate Gel Autocombustion Method
}

\author{
G. Aravind, ${ }^{1}$ D. Ravinder, ${ }^{1}$ and V. Nathanial ${ }^{2}$ \\ ${ }^{1}$ Department of Physics, Osmania University, Hyderabad, Telangana 500007, India \\ ${ }^{2}$ Department of Physics, University College of Science, Osmania University, Saifabad, Telangana 500044, India
}

Correspondence should be addressed to D. Ravinder; ravindergupta28@rediffmail.com

Received 9 July 2014; Revised 19 September 2014; Accepted 21 September 2014; Published 20 October 2014

Academic Editor: Israel Felner

Copyright (C) 2014 G. Aravind et al. This is an open access article distributed under the Creative Commons Attribution License, which permits unrestricted use, distribution, and reproduction in any medium, provided the original work is properly cited.

\begin{abstract}
An attempt has been made to synthesize nanocrystalline lithium-nickel ferrites with a compositional formula $\mathrm{Li}_{0.5-0.5 x} \mathrm{Ni}_{x} \mathrm{Fe}_{2.5-0.5 x} \mathrm{O}_{4}$ (where $x=0.0$ to 1.0 with step of 0.2 ) by a low temperature citrate gel autocombustion method. Single phase cubic structure is confirmed by X-ray diffraction analysis. This result demonstrates that the prepared samples are homogeneous and the sharp peaks reveal that the samples are in good crystalline form. As the Ni concentration is increased, various interesting changes in the values of the structural parameters like lattice parameter, X-ray density, bulk density, and porosity have been observed. The surface morphology of the prepared samples was studied using scanning electron microscopy (SEM). The DC resistivity measurements were carried out using two-probe method from $200^{\circ} \mathrm{C}$ to $600^{\circ} \mathrm{C}$. The variation of $\log (\sigma T)$ with reciprocal of temperature shows a discontinuity at Curie temperature. $\log (\sigma T)$ versus $1 / T$ plot of the pure lithium ferrites is almost linear which indicates the Curie temperature of the pure lithium ferrites was beyond our measured temperature. The dielectric properties of these ferrites have been studied using a LCR meter from the room temperature to $700 \mathrm{~K}$ at various frequencies up to $5 \mathrm{MHz}$, which reveals that all the prepared samples have dielectric transition temperature around $600 \mathrm{~K}$.
\end{abstract}

\section{Introduction}

The spinel magnetic ferrites have generated considerable interest among the researchers all across the world, due to their unique and versatile properties. Novel electrical and magnetic behaviors are observed for the nanosized magnetic particles when compared to that of the bulk counterparts [1]. In the early days, garnets were used for microwave devices where they have high value of electrical resistivity and low dielectric losses. But because of low Curie temperature, high stress sensitivity, and high cost of the garnets, they are rarely used. Recently, spinel ferrites are often used in place of garnets. Lithium ferrites and substituted lithium ferrites have become important materials for the microwave applications such as in circulators, isolators, and phase shifters due to their high resistivity, low dielectric losses, high Curie temperature, square hysteresis loop, and low cost [2-6].

In the inverse spinel lithium ferrite structure, $\mathrm{Li}_{0.5} \mathrm{Fe}_{2.5} \mathrm{O}_{4}$, $\mathrm{Li}^{+}$and $3 / 5$ th of the $\mathrm{Fe}^{+3}$ ions occupy octahedral sites (B-sites) of cubic spinel structure, $\mathrm{AB}_{2} \mathrm{O}_{4}$. The distribution of cations in the inverse spinel structure of lithium ferrite is given by $\left(\mathrm{Fe}^{+3}\right)\left[\mathrm{Li}_{0.5}^{+1} \mathrm{Fe}^{+3}{ }_{0.5} \mathrm{Fe}^{+3}\right] \mathrm{O}_{4}$, where parentheses and square brackets indicate the ion distribution on tetrahedral (A-site) and octahedral (B-site) sites, respectively $[7,8]$.

The diverse properties of spinel lithium ferrites originate from their ability to incorporate a variety of transition metal cations into their lattice, causing a subsequent change in their structural, optical, magnetic, and electrical properties $[9,10]$. The observed changes in these properties are brought about by a redistribution of cations among the tetrahedral and octahedral sites of the ferrite sublattice. The substitution of various metal ions into the lattice of the lithium ferrite gives rise to materials with new and interesting properties. This is because the degree of inversion in the substituted lithium ferrites and, therefore, their properties are found to be strongly dependent on the preparation conditions (method of preparation, sintering time, sintering temperature, $\mathrm{pH}$ value, etc.), amount of the substituent and type of substitution, and 


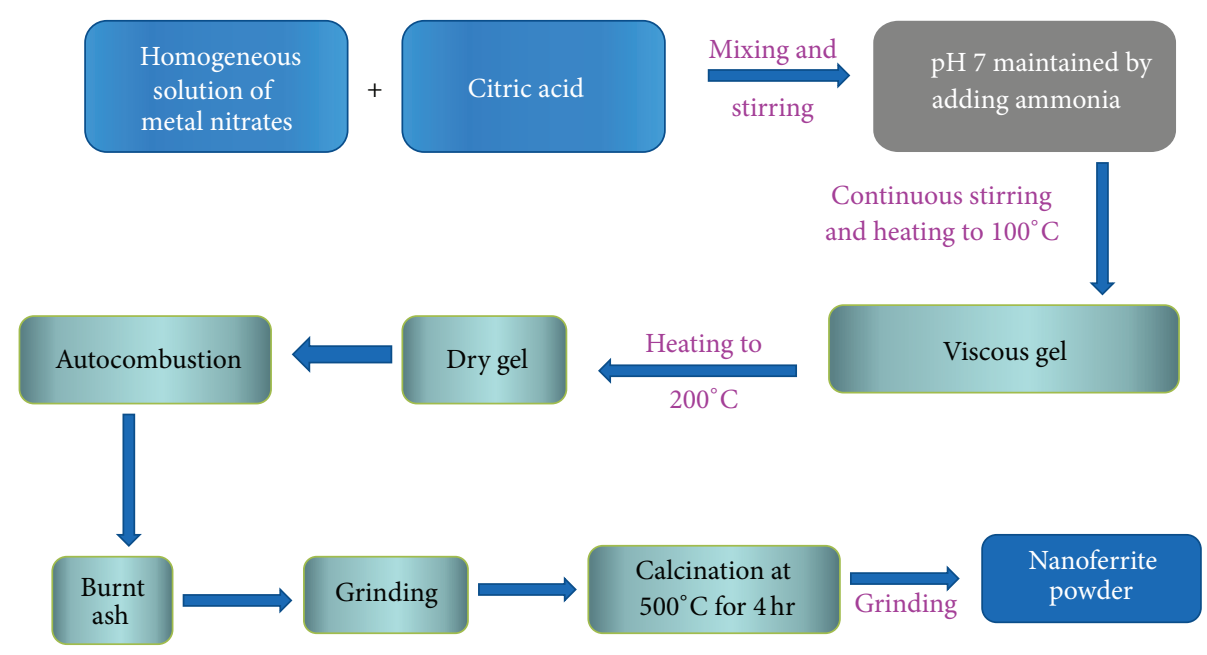

FIGURE 1: Schematic diagram representing preparation of nanoferrites.

so forth. The DC electrical conductivity of ferrites is one of the important properties, which gives the valuable information about the conduction mechanism. Moreover, electrical conductivity has a significant effect on the dielectric polarization in the spinel ferrites.

Several methods are used for synthesizing nanosized spinel ferrites such as coprecipitation, sol-gel, microemulsion, hydrothermal, citrate gel, and reverse micelle methods [11-13]. In the preparation of lithium based ferrites, low temperature sintering is needed to suppress lithium volatility and oxygen loss during sintering. Many researchers proposed the citrate gel method is a simple route to synthesize materials in the nanocrystalline form due to lower sintering temperature. Several investigations on the properties of the Li-Cd [14], Li$\mathrm{Zn} \mathrm{[15],} \mathrm{and} \mathrm{Li-Mg} \mathrm{[16]} \mathrm{ferrites} \mathrm{have} \mathrm{been} \mathrm{reported.} \mathrm{Mazen}$ and Elmosalami [17] and Bhatu et al. [18] have synthesized nickel substituted lithium ferrites by ceramic method with high sintering temperature. However there are no detail reports on $\mathrm{Ni}$ substituted lithium nanoferrites prepared by citrate gel autocombustion method with low sintering temperature.

In the present study, we report the synthesis of nickel substituted lithium nanoferrites by nonconventional citrate gel autocombustion method; XRD studies of prepared samples, SEM micrographs, temperature dependent DC conductivity studies, and the dielectric properties of these ferrites from the room temperature to $700 \mathrm{~K}$ at various selected frequencies up to $5 \mathrm{MHz}$ have been studied.

\section{Experimental Techniques}

Nanocrystalline nickel substituted lithium ferrites having the chemical formula $\mathrm{Li}_{0.5-0.5 x} \mathrm{Ni}_{x} \mathrm{Fe}_{2.5-0.5 x} \mathrm{O}_{4}$ (where $x=0.0$ to 1.0 with step of 0.2 ) were synthesized using citrate gel autocombustion method. This method has certain inherent advantages like low processing temperature $\left(200^{\circ} \mathrm{C}\right)$, good stoichiometric control, and homogeneous distribution of reactants and production of ultrafine particles with narrow size distribution. In this citrate gel autocombustion method, metal nitrates act as oxidizing agents and organic fuels as reducing agents $[19,20]$. The various powder properties can be systematically tuned by altering the oxidant to fuel ratios. In present study fuel to oxidizing ratio was maintained at unity. The detailed synthesis process is represented in Figure 1.

The stoichiometric amounts of ferric nitrate $\left(\mathrm{Fe}\left(\mathrm{NO}_{3}\right)_{2}\right.$ $\left.9 \mathrm{H}_{2} \mathrm{O}\right)$, Nickel nitrate $\left(\mathrm{Ni}\left(\mathrm{NO}_{3}\right)_{2} 6 \mathrm{H}_{2} \mathrm{O}\right)$, lithium nitrate $(\mathrm{LiNO})$, and citric acid $\left(\mathrm{C}_{6} \mathrm{H}_{8} \mathrm{O}_{7} \cdot \mathrm{H}_{2} \mathrm{O}\right)$ (all chemicals are S.D. Fine-Chem Limited) were weighed and dissolved separately in minimum amount of distilled water. All the individual solutions were mixed together and then the ammonia solution was slowly added to adjust the $\mathrm{pH}$ value at 7. The proliferation of nitrate ions at low $\mathrm{pH}$ value is likely to decrease the enthalpy of exothermic reaction by decreasing the fuel to oxidizing ratio. Thus, the rate of combustion reaction decreases and particles agglomerate [21] so the $\mathrm{pH}$ value of the solution was maintained at 7 , to avoid the agglomeration and preserve the stoichiometry. The resultant solution was kept on a hot plate magnetic stirrer at $100^{\circ} \mathrm{C}$ till gels were formed; after that, increasing the temperature up to $200^{\circ} \mathrm{C}$, the gels self-ignited in an autocombustion manner till whole citrate complex was consumed to yield nanoferrite powders. The as synthesized ferrite powders were annealed at $500^{\circ} \mathrm{C}$ for 4 hours in a muffle furnace [22].

The structural characterization of the synthesized samples was carried out by Philips X-ray diffractometer (Model 3710) using $\mathrm{Cu} \mathrm{K}_{\alpha}$ radiation of wavelength $1.5405 \AA$ at room temperature by continuous scanning in the range of Bragg's angles $5^{\circ}$ to $80^{\circ}$ in steps of $2^{\circ} / \mathrm{min}$ to investigate the phase and crystalline size.

The average crystalline size of the ferrites was determined from the measured width of their diffraction pattern using Debye Scherer's formula

$$
D=\frac{0.91 \lambda}{\beta \cos \theta},
$$

where $\lambda$ is the wavelength of the X-ray used for diffraction and $\beta$ is the full width half maximum (FWHM) in radians. 
The lattice constant was calculated using the following relation:

$$
2 d \sin \theta=n \lambda,
$$

where $d=a /\left(h^{2}+k^{2}+l^{2}\right)^{1 / 2}$ for Fcc system.

The X-ray density $\left(d_{x}\right)$ has been calculated according to the relation

$$
d_{x}=\frac{8 M}{a^{3} N} \quad\left[\mathrm{gm} / \mathrm{cm}^{3}\right]
$$

where $M=$ molecular weight of the sample. $a$ is the lattice parameter and $N$ is the Avogadro number.

The volume of the unit cell $V=a^{3}$.

The experimental density of the prepared sample was calculated by Archimedes' principle with xylene media using following relation:

$$
d_{E}=\frac{w_{\text {air }}}{w_{\text {air }}-w_{\text {xylene }}} \times \text { density of xylene, }
$$

where $w_{\text {air }}$ is weight of the sample in air, $w_{\text {xylene }}$ is the weight of the sample in xylene.

Porosity $P$ of the ferrite sample was then determined by employing the relation

$$
P=d_{x}-\frac{d_{E}}{d_{x}}
$$

The powders of different compositions were pressed into disc shaped pellets of $13 \mathrm{~mm}$ diameter by applying a pressure of $2.5 \times 10^{8} \mathrm{~N} / \mathrm{m}^{2}$. Silver coating was done on adjacent faces of circular disc shaped pellets to have good ohmic contact and also to make parallel plate capacitor geometry with ferrite material as a dielectric medium.

The DC electrical conductivities of nanoferrite materials were measured by two-probe technique in the temperature range $473-873 \mathrm{~K}$. The measurements were recorded in the steps of $10 \mathrm{~K}$.

The dielectric parameters like dielectric constant $\left(\varepsilon^{\prime}\right)$ and dielectric loss tangent $(\tan \delta)$ were measured using Agilent E4986A precession LCR meter in the temperature range $313 \mathrm{~K}-723 \mathrm{~K}$ at selected frequencies $(7.5 \mathrm{kHz}, 30 \mathrm{kHz}$, $600 \mathrm{kHz}, 1 \mathrm{MHz}, 3 \mathrm{MHz}$, and $5 \mathrm{MHz}$ ) up to $5 \mathrm{MHz}$ frequency.

The dielectric constant of prepared sample was calculated using the following relation:

$$
\varepsilon^{\prime}=\frac{C t}{\varepsilon_{o} A}
$$

where $C$ is the capacitance of the pellet, $t$ is the thickness of the sample pellet, $A$ is the cross section area of pellet, and $\varepsilon_{o}$ is the free space permittivity.

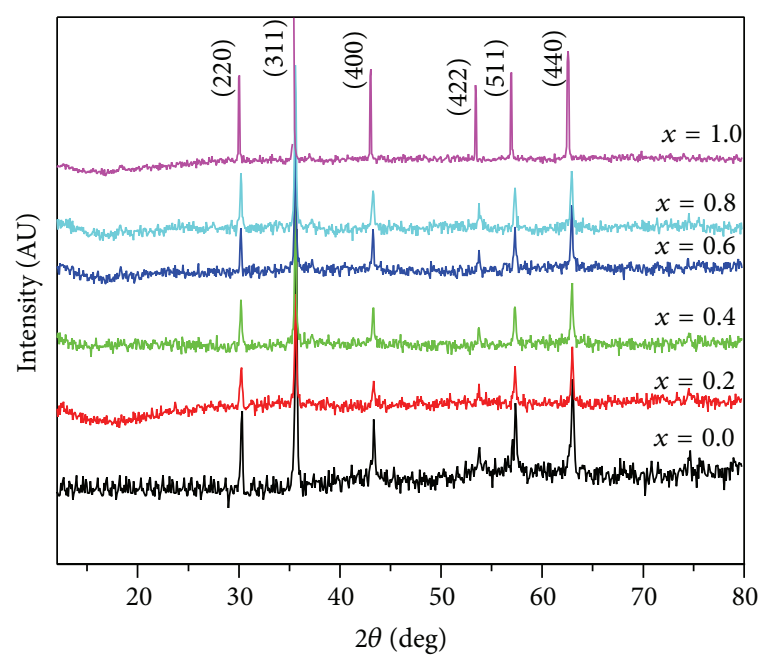

FIGURE 2: XRD pattern of the $\mathrm{Li}_{0.5-0.5 x} \mathrm{Ni}_{x} \mathrm{Fe}_{2.5-0.5 x} \mathrm{O}_{4}$ nanoferrites.

\section{Results and Discussion}

3.1. Structural Analysis. The structural study is essential for optimizing the properties needed for various applications. The phase identification and lattice constant determination of the prepared samples were performed on the X-ray diffraction analysis. The obtained XRD pattern of the nickel substituted lithium nanoferrites samples having chemical formula $\mathrm{Li}_{0.5-0.5 x} \mathrm{Ni}_{x} \mathrm{Fe}_{2.5-0.5 x} \mathrm{O}_{4}$ (where $x=0.0$ to 1.0 with step of 0.2 ) sintered at $500^{\circ}$ for 4 hours was shown in Figure 2. The XRD patterns of the calcined $\mathrm{Li}-\mathrm{Ni}$ nanoferrite powders (shown in Figure 2) confirm the formation of a single phase cubic spinel structure with no extra impurity diffraction lines. The strong diffraction from the (220), (311), (400), (422), (511), and (440) planes confirms the pure spinel phase of the annealed ferrites $[23,24]$. The XRD pattern perfectly matches with the standard pattern with JCPDS reference code 00-013-0207.

The average crystallite size of the prepared nanoferrite samples was in the ranges from 39 to $49 \mathrm{~nm}$ for different doping levels of the $\mathrm{Ni}^{+2}$ ions (Table 1). The lattice constant $(a)$ is found to be increased with the increasing of the $\mathrm{Ni}^{+2}$ ion concentration (Table 1). This is obvious because $\mathrm{Ni}^{+2}$ ions have the larger ionic radii $(0.78 \AA)$ than that of $\mathrm{Li}^{+1}$ ion $(0.76 \AA)$ and $\mathrm{Fe}^{+3}$ ion $(0.67 \AA)$ and obey Vegard's law $[25,26]$. The substitution by the larger ions results in expansion of lattice. An increase in the lattice parameter when Li and Fe were replaced by $\mathrm{Ni}$, as observed in the present work, is therefore expected. The observed deviation in the value of lattice parameter can be attributed to the rearrangement of cations in the nanosized $\mathrm{Li}-\mathrm{Ni}$ ferrites consequent to the sintering process.

$\mathrm{X}$-ray density values of the $\mathrm{Li}-\mathrm{Ni}$ nanoferrites were increased with increasing the $\mathrm{Ni}$ concentration because molecular weight of the samples increases with increasing the $\mathrm{Ni}$ composition. It is noted that X-ray density of each sample $\left(d_{x}\right)$ is greater than the corresponding bulk density $\left(d_{e}\right)$ which is an evidence of the presence of pores in the samples.

The surface morphology of the Li-Ni nanoferrite particles sintered at $500^{\circ} \mathrm{C}$ was examined by scanning electron 
TABLE 1: Crystalline size, lattice parameter, X-ray density, bulk density, and porosity of Li-Ni nanoferrites obtained from XRD analysis.

\begin{tabular}{lccccccc}
\hline S. No. & Composition & $\begin{array}{c}\text { Mol. wt } \\
(\mathrm{gm} / \mathrm{mole})\end{array}$ & $\begin{array}{c}\text { Crystallite } \\
\text { size }(\mathrm{nm})\end{array}$ & $\begin{array}{c}\text { Lattice parameter } \\
\left(\mathrm{A}^{\circ}\right)\end{array}$ & $\begin{array}{c}\text { X-ray density }\left(d_{x}\right) \\
(\mathrm{gm} / \mathrm{cc})\end{array}$ & $\begin{array}{c}\text { Expt. density }\left(d_{e}\right) \\
(\mathrm{gm} / \mathrm{cc})\end{array}$ & \begin{tabular}{c} 
Porosity $(P)$ \\
\hline 1
\end{tabular} \\
\hline $\mathrm{Li}_{0.5} \mathrm{Fe}_{2.5} \mathrm{O}_{4}$ & 207.079 & 41.90 & 8.356 & 4.713 & 4.286 & 9.01 \\
2 & $\mathrm{Li}_{0.4} \mathrm{Ni}_{0.2} \mathrm{Fe}_{2.4} \mathrm{O}_{4}$ & 212.538 & 39.54 & 8.356 & 4.839 & 4.319 & 10.70 \\
3 & $\mathrm{Li}_{0.3} \mathrm{Ni}_{0.4} \mathrm{Fe}_{2.3} \mathrm{O}_{4}$ & 217.998 & 45.35 & 8.358 & 4.957 & 4.329 & 12.66 \\
4 & $\mathrm{Li}_{0.2} \mathrm{Ni}_{0.6} \mathrm{Fe}_{2.2} \mathrm{O}_{4}$ & 223.458 & 49.90 & 8.361 & 5.076 & 4.553 & 10.31 \\
5 & $\mathrm{Li}_{0.1} \mathrm{Ni}_{0.8} \mathrm{Fe}_{2.1} \mathrm{O}_{4}$ & 228.918 & 41.30 & 8.368 & 5.206 & 4.568 & 12.22 \\
6 & $\mathrm{NiFe}_{2} \mathrm{O}_{4}$ & 234.379 & 43.01 & 8.374 & 5.334 & 4.742 & 11.07 \\
\hline
\end{tabular}
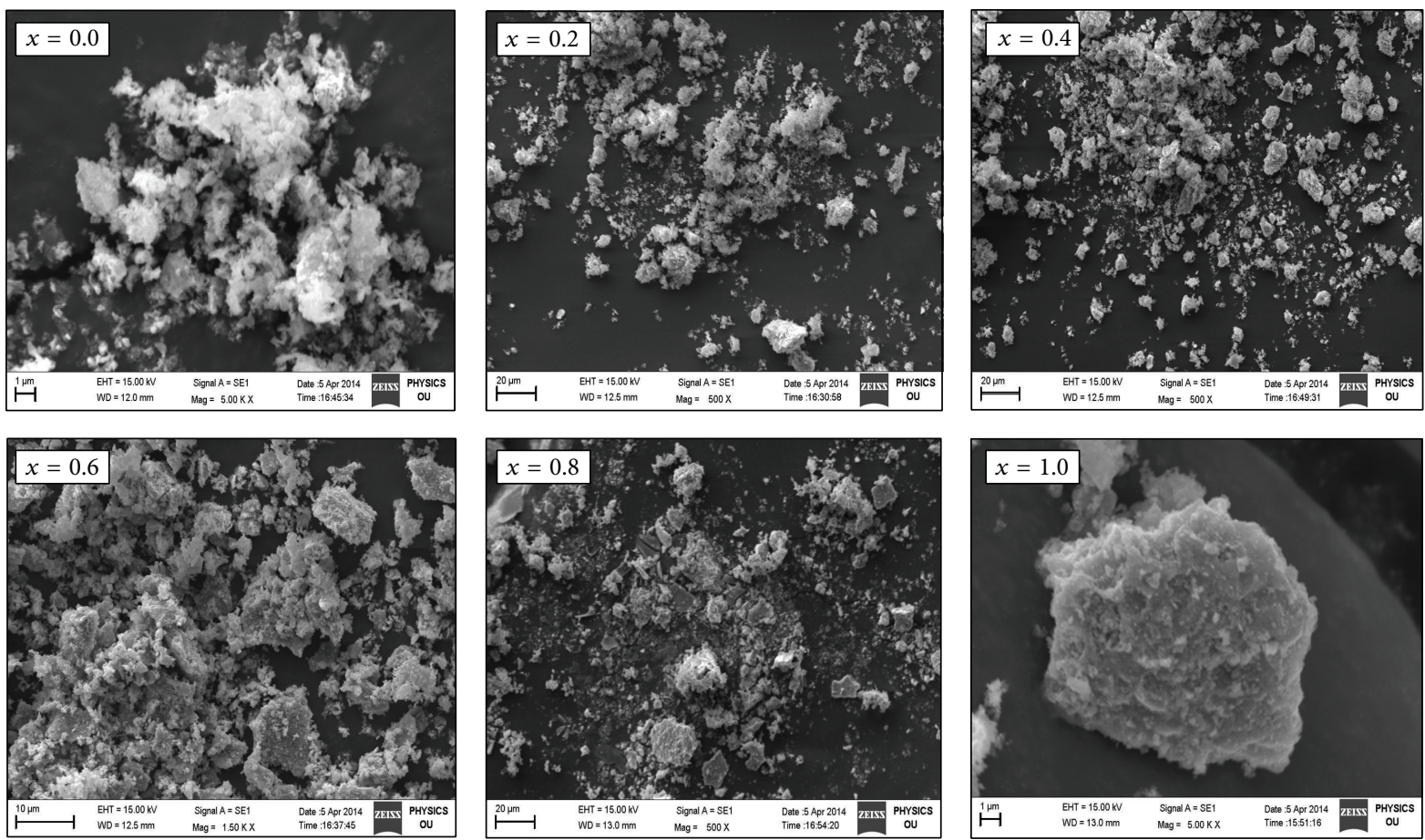

(a)
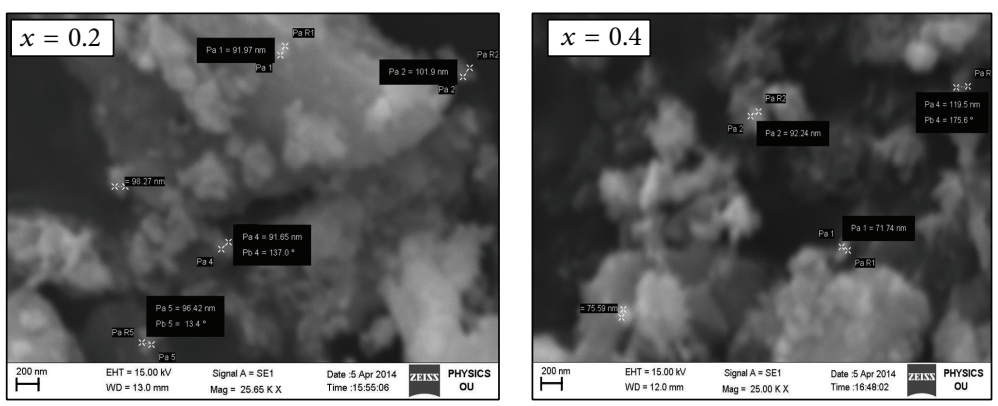

(b)

Figure 3: (a) SEM images of the $\mathrm{Li}_{0.5-0.5 x} \mathrm{Ni}_{x} \mathrm{Fe}_{2.5-0.5 x} \mathrm{O}_{4}$ nanoferrites. (b) SEM images with grain size of the samples at $x=0.2$ and $x=0.4$.

microscopy (SEM) shown in Figure 3(a) which indicates the agglomerated nanoparticles which is attributed to the magnetic exchange interaction between the nanoparticles. It is observed that the average grain size of the prepared samples goes on increasing on substitution of $\mathrm{Ni}$ in the place of $\mathrm{Li}$ and Fe in ferrites. The average grain size of all the prepared samples directly calculated from SEM instrument is in the range of 50-130 nm only. The SEM images of samples $x=0.2$ and $x=0.4$ with grain size were shown in Figure 3(b) and grain size of remaining samples is also in the same range (the figures are not shown).

3.2. Electrical Properties. The DC electrical conductivity of the prepared samples was measured by two-probe method 
TABLE 2: Electrical resistivity and activation energies of the $\mathrm{Li}_{0.5-0.5 x} \mathrm{Ni}_{x} \mathrm{Fe}_{2.5-0.5 x} \mathrm{O}_{4}$ system.

\begin{tabular}{lccccc}
\hline S. No. & Composition & $\begin{array}{c}\text { Resistivity } \\
(\Omega \text {-cm) }\end{array}$ & Curie temp. $\left({ }^{\circ} \mathrm{C}\right)$ & $\begin{array}{c}E_{a} \text { in paramagnetic } \\
\text { region }(\mathrm{eV})\end{array}$ & $\begin{array}{c}E_{a} \text { in Ferromagnetic } \\
\text { region }(\mathrm{eV})\end{array}$ \\
\hline 1 & $\mathrm{Li}_{0.5} \mathrm{Fe}_{2.5} \mathrm{O}_{4}$ & $9.21 \times 10^{8}$ & - & - & - \\
2 & $\mathrm{Li}_{0.4} \mathrm{Ni}_{0.2} \mathrm{Fe}_{2.4} \mathrm{O}_{4}$ & $9.17 \times 10^{8}$ & 567 & 1.61 & 0.82 \\
3 & $\mathrm{Li}_{0.3} \mathrm{Ni}_{0.4} \mathrm{Fe}_{2.3} \mathrm{O}_{4}$ & $5.73 \times 10^{8}$ & 560 & 1.27 & 0.93 \\
4 & $\mathrm{Li}_{0.2} \mathrm{Ni}_{0.6} \mathrm{Fe}_{2.2} \mathrm{O}_{4}$ & $2.73 \times 10^{8}$ & 540 & 0.95 & 0.83 \\
5 & $\mathrm{Li}_{0.1} \mathrm{Ni}_{0.8} \mathrm{Fe}_{2.1} \mathrm{O}_{4}$ & $1.24 \times 10^{7}$ & 535 & 0.90 & 0.73 \\
6 & $\mathrm{NiFe}_{2} \mathrm{O}_{4}$ & $6.82 \times 10^{7}$ & 528 & 0.81 & 0.71 \\
\hline
\end{tabular}

in the temperature range from $473 \mathrm{~K}$ to $873 \mathrm{~K}$. The ferrite sample is pressed into circular pellets. The measurements were recorded in the steps of $10 \mathrm{~K}$.

The temperature dependence of the prepared ferrites conductivity is plotted in accordance with the following Arrhenius type equation:

$$
\log \sigma=\log \sigma_{o}-\frac{E_{a}}{K_{B} T}
$$

where $\sigma$ is the conductivity, $\sigma_{o}$ is the conductivity at absolute temperature, $K_{B}$ is Boltzmann's constant, and $T$ is the temperature. The phenomenon of phase transition, cation migration, cation reordering, the presence of impurities, and magnetotransport effects are considered to be responsible for the temperature dependence on the electrical conductivity of the prepared ferrite samples.

The variations of the electrical conductivity $(\log \sigma T)$ with inverse of temperature $(1000 / T)$ were shown in Figure 4. The conductivity of the ferrite samples increases with increasing the temperature. That is, temperature increases and resistivity of the ferrites was decreased, indicating the semiconducting behaviour. All the plots (except pure lithium ferrites) of electrical conductivity $(\log \sigma T)$ versus $1000 / T$ yield a change in slope at a particular temperature. This change in slope occurs while crossing the Curie temperature (the temperature at which the ferromagnetic material changed to paramagnetic). The discontinuity at the Curie temperature was attributed to the magnetic transition from well-ordered ferromagnetic state to disordered paramagnetic state which involves different activation energies. The values of the electrical resistivity and thermal activation energies of the prepared samples at ferromagnetic region and paramagnetic region were given in Table 2.

It is observed that the activation energy in the ferromagnetic region is smaller than the paramagnetic region; this is due to the effect of spin disordering.

Some workers have reported three regions of conductivity [26-29] of which the first region has been attributed to the presence of impurities, second region was due to the phase transition from tetragonal structure to cubic structure, and the third one was due to the ferromagnetic to paramagnetic change. The electrical conductivity of ferrites can be explained on the basis of the Verwey and de Boer mechanism [30] which involves the exchange of charge carriers, that is, electrons between the ions of the same element that are present in more than one valence state $\left(\mathrm{Fe}^{+2}, \mathrm{Fe}^{+3}\right)$, distributed randomly over the crystallographic lattice sites. The $\mathrm{Fe}^{+2}$ ion concentration is a characteristic property of nanoferrites and it depends on several factors such as sintering temperature/time and atmosphere and annealing time including the grain structure. Some amount of $\mathrm{Fe}^{+2}$ ions is also formed due to possible evaporation of $\mathrm{Li}$ ions during the sintering [28]. Sintering of lithium ferrites is therefore carried out at relatively lower temperature $\left(500^{\circ} \mathrm{C}\right)$ in order to avoid lithium loss during sintering.

The variation of DC electrical resistivity at $200^{\circ} \mathrm{C}$ with $\mathrm{Ni}$ composition in the Li ferrites is given in Table 2. The DC resistivity of the all the samples was observed to be in the range $1.24 \times 10^{7}-9.21 \times 10^{8} \Omega-\mathrm{cm}$. Compositionally decrease in the $\mathrm{DC}$ resistivity of $\mathrm{Li}-\mathrm{Ni}$ ferrites with increasing the $\mathrm{Ni}$ concentration was observed. The overall higher values of resistivity obtained for the ferrites can be attributed to the small grain size and better compositional stoichiometry with reduced $\mathrm{Fe}^{+2}$ formation as a result of low temperature processing by the citrate gel method [31,32].

3.3. Dielectric Properties. The dielectric constant and DC electrical resistivity of ferrites are very important parameters from the application point of view. These two parameters are electrical properties and exchange of electrons between the $\mathrm{Fe}^{+2}$ and $\mathrm{Fe}^{+3}$ ions is responsible for these mechanisms which results in local displacement of charges responsible for the polarisation in ferrites. The dielectric constant $\left(\varepsilon^{\prime}\right)$ and dielectric loss tangent $(\tan \delta)$ were found to be dependent on the variation of external factors such as temperature and frequency. The variation of dielectric constant $\left(\varepsilon^{\prime}\right)$ and dielectric loss tangent $(\tan \delta)$ with respect to selected frequencies and temperature in the range of $300 \mathrm{~K}$ to $700 \mathrm{~K}$ has been investigated.

The variation of dielectric constant $\left(\varepsilon^{\prime}\right)$ and dielectric loss tangent $(\tan \delta)$ for all prepared ferrite samples with temperature has been studied at different frequencies as shown in Figures 5(a) and 5(b).

It is observed that the dielectric constant $\left(\varepsilon^{\prime}\right)$ and dielectric loss tangent $(\tan \delta)$ of prepared samples were increased with increase in temperature for all selected frequencies. The increase in temperature of the sample thermally activates the charge carrier, increasing the electron exchange interaction which results in increasing the dielectric constant values of 

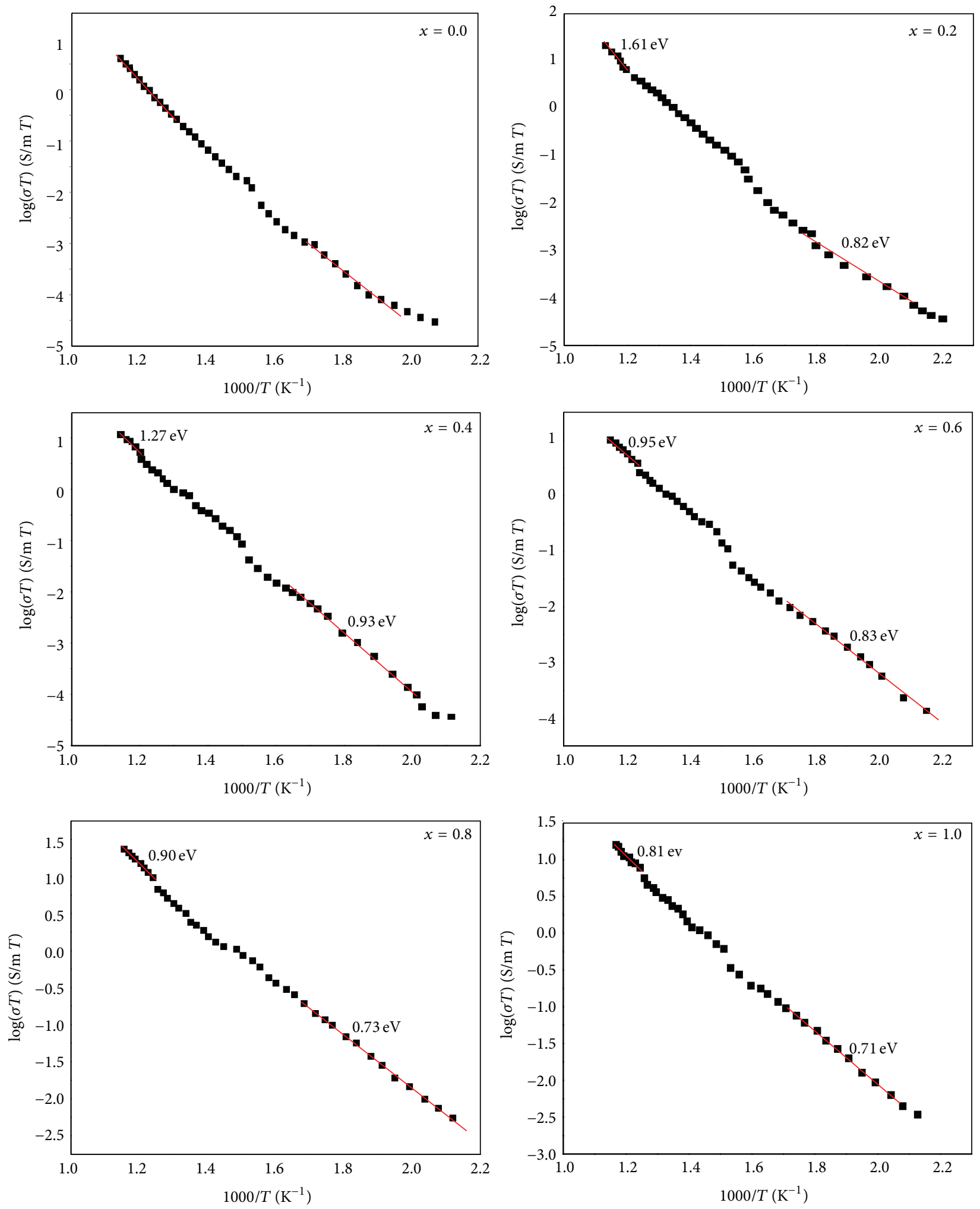

FIgURE 4: Arrhenius plots for electrical conductivities of $\mathrm{Li}_{0.5-0.5 x} \mathrm{Ni}_{x} \mathrm{Fe}_{2.5-0.5 x} \mathrm{O}_{4}$ nanoferrites. 

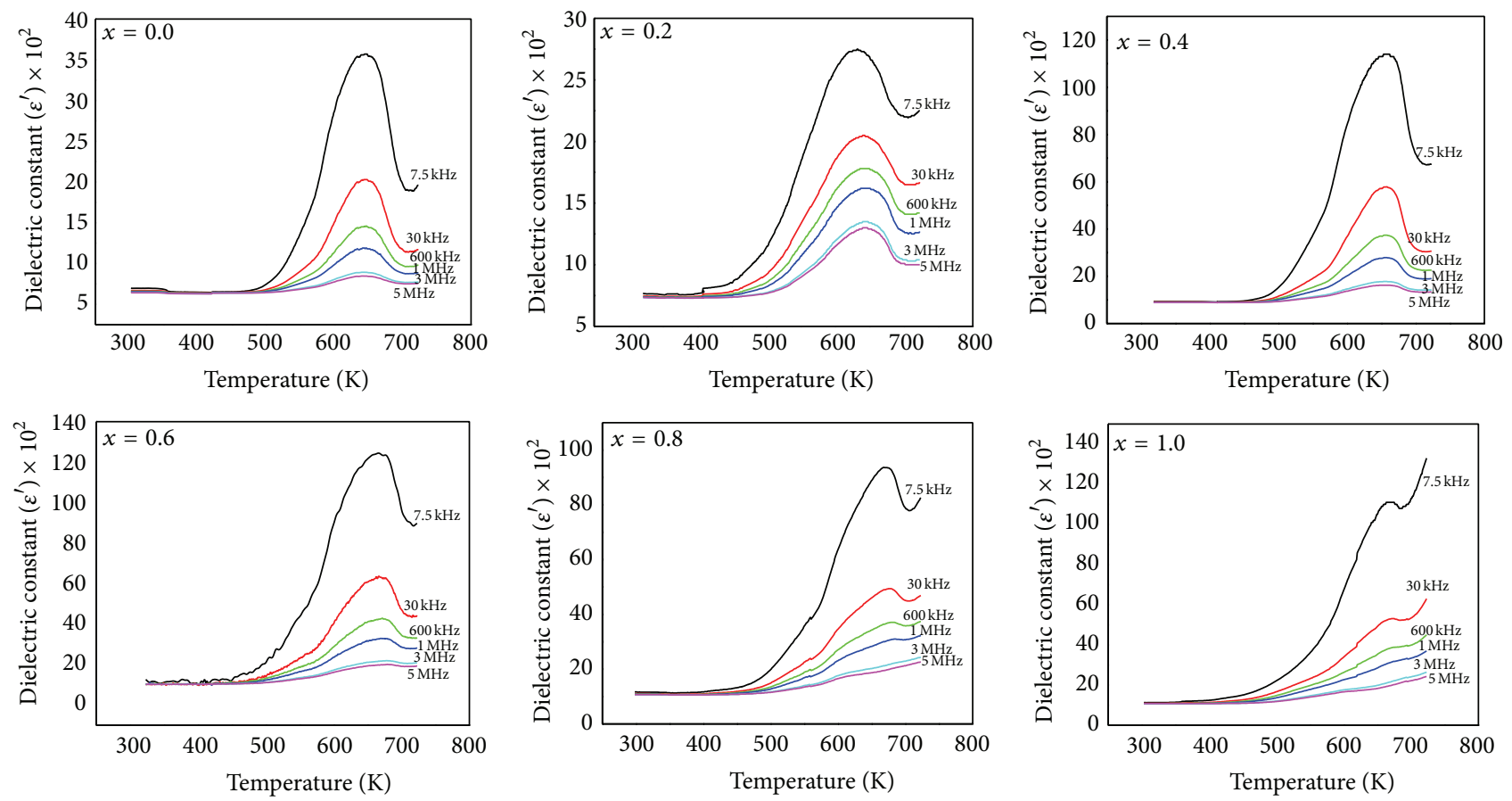

(a)
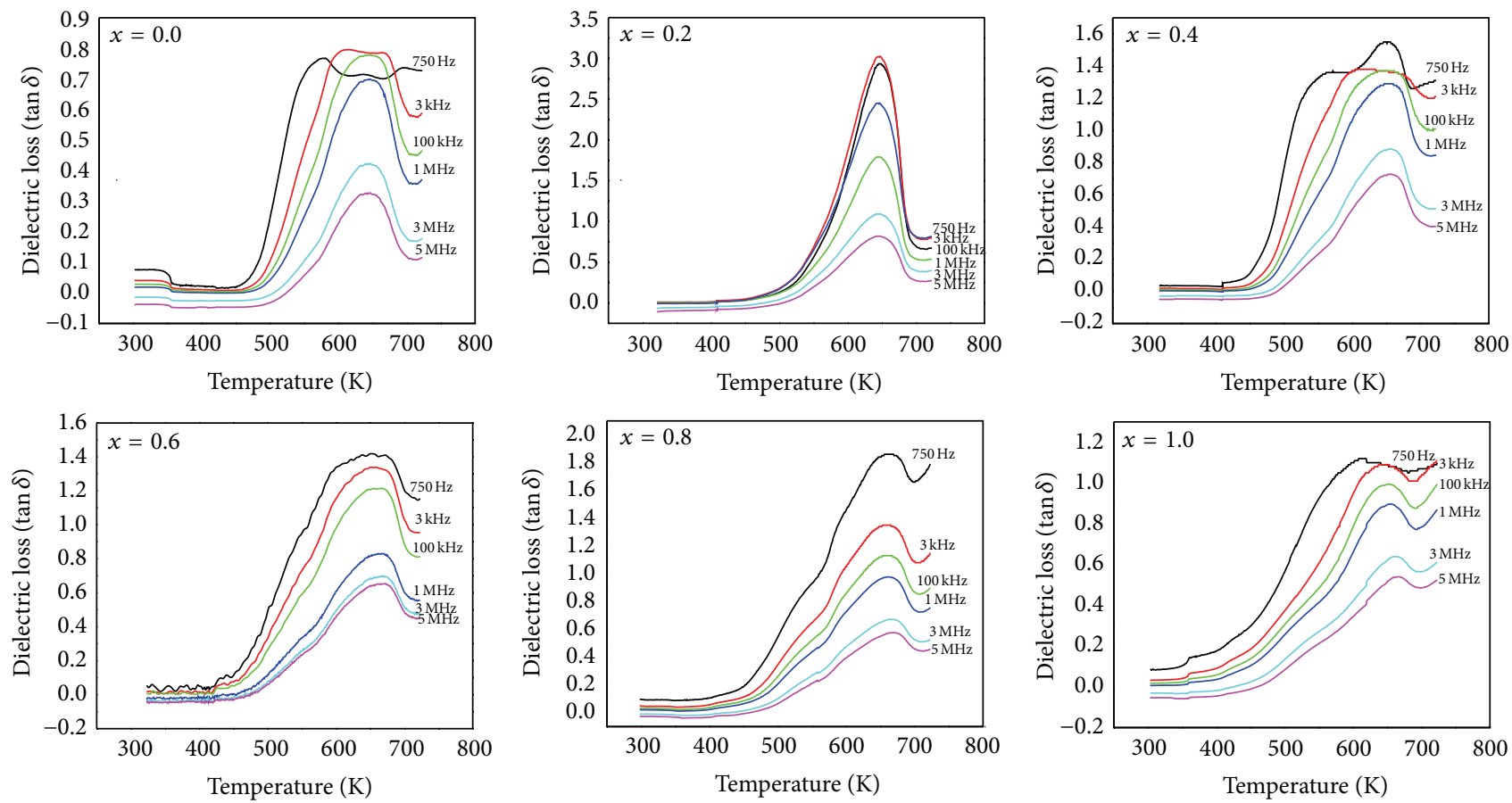

(b)

Figure 5: (a) Variation of dielectric constant $\left(\varepsilon^{\prime}\right)$ with temperature at different frequencies of $\mathrm{Li}_{0.5-0.5 x} \mathrm{Ni}_{x} \mathrm{Fe}_{2.5-0.5 x} \mathrm{O}_{4}$ nanoferrites. (b) Variation of loss tangent $\left(\tan \delta\right.$ ) with temperature at different frequencies of $\mathrm{Li}_{0.5-0.5 x} \mathrm{Ni}_{x} \mathrm{Fe}_{2.5-0.5 x} \mathrm{O}_{4}$ nanoferrites.

the ferrites. It is observed that there are four major contributions for polarisation in ferrites. They are electronic, atomic, dipolar, and interfacial polarisations [33]. Electronic and atomic polarisations are important at high frequencies and are independent of temperature while remaining two are important at lower frequencies and dependent on temperature. By increasing the temperature interfacial polarisation is increased and dipolar polarisation decreases. The increase in dielectric constant with increase in temperature at low frequency may be due to the interfacial polarisation. 


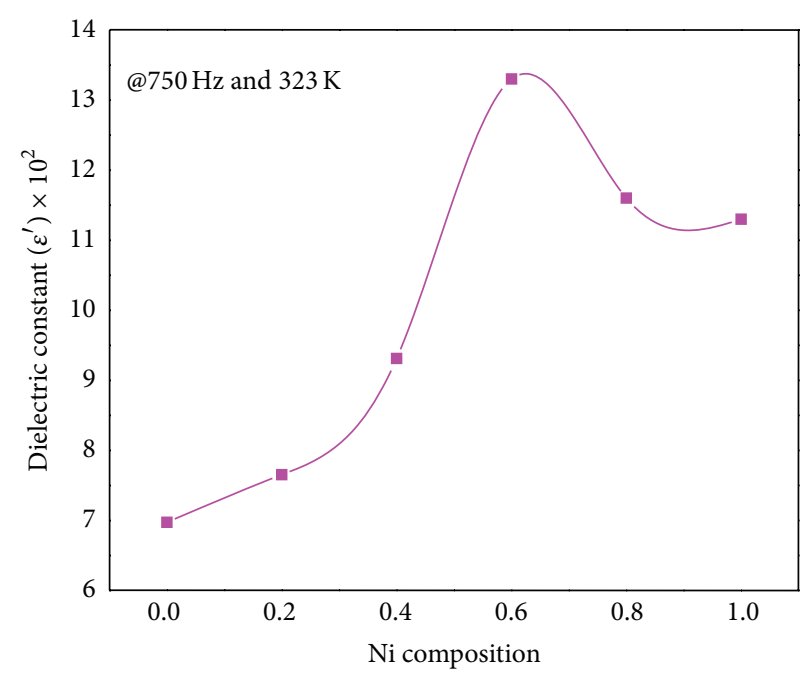

(a)

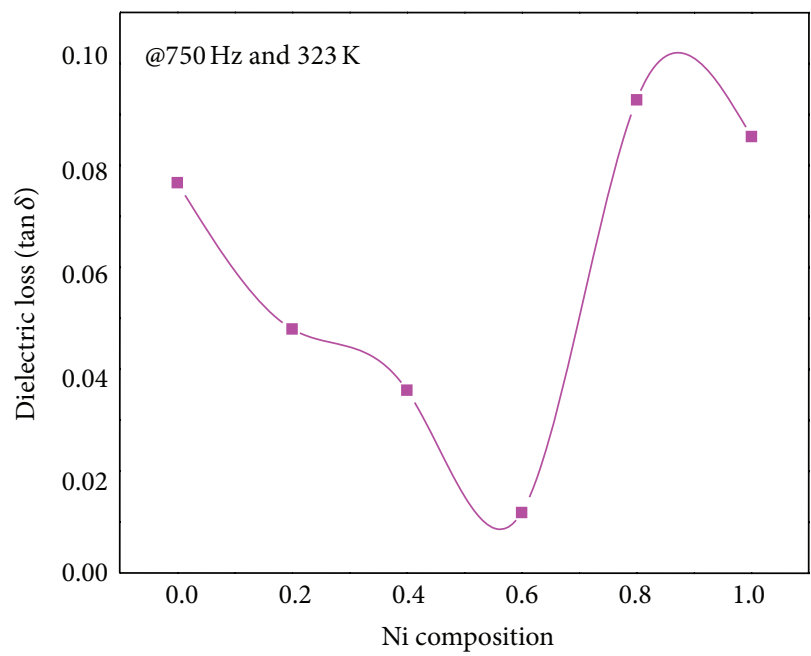

(b)

FIGURE 6: Variation of dielectric constant $\left(\varepsilon^{\prime}\right)$ and $\tan \delta$ with Ni concentration.

From Figure 5(a) it can be noticed that the dielectric constant $\left(\varepsilon^{\prime}\right)$ values increase rapidly in the low temperature range $(T<600 \mathrm{~K})$, whereas in the high temperature range $(T>600 \mathrm{~K})$ dielectric constant $\left(\varepsilon^{\prime}\right)$ reaches a stable value (Resonance peak); after that it starts to decrease with increasing the temperature. For the low temperature range $(T<600 \mathrm{~K})$, the polarisation is increased by the electric field and also by increasing the number of charge carriers (electrons) which are increased with temperature; hence the increase in the dielectric constant $\left(\varepsilon^{\prime}\right)$ at low temperature range $(T<600 \mathrm{~K})$ is due to increase in both temperature and frequency. For the high temperature range $(T>600 \mathrm{~K})$, the saturation in the generation of charge carriers is reached. Therefore the electron exchange between the ions of the same element that are present in more than one valence state $\left(\mathrm{Fe}^{+2}\right.$, $\mathrm{Fe}^{+3}$ or $\mathrm{Ni}^{+2}, \mathrm{Ni}^{+1}$ ) cannot follow the field variation and hence dielectric constant decreases [34]. The temperature at which the resonance peak appeared is observed to be shifted towards the higher temperature as the frequency is increased [35]. The variation of loss angle tangent $(\tan \delta)$ of the prepared sample as a function temperature at different frequencies has also been investigated and an increase is observed just as the dielectric constant $\left(\varepsilon^{\prime}\right)$ curve. This variation of loss tangent with temperature curve can be understood on the basis of Debye's equation for loss given as [33].

The compositional dependence (Ni concentration) of the dielectric constant $\left(\varepsilon^{\prime}\right)$ and dielectric loss tangent $(\tan \delta)$ of prepared samples at $323 \mathrm{~K}$ and at $75 \mathrm{kHz}$ is shown in Figure 6. It can be observed that the dielectric constant $\left(\varepsilon^{\prime}\right)$ value of the prepared samples was increased from $x=0.0$ to $x=$ 0.6 and then decreased. It can be attributed to the effect of simultaneous contributions of different factors such as grain size, density, porosity, and cation distribution. The initial increase in dielectric constant $\left(\varepsilon^{\prime}\right)$ when Ni content increases from $x=0.0$ to $x=0.6$ coincides with the increase of grain size from Table 1 [36]. After that the cation distribution becomes the predominant factor in decreasing the dielectric constant $\left(\varepsilon^{\prime}\right)$ with $\mathrm{Ni}$ content since the decrease of hole hoping becomes greater than the increase of electron hoping in the B-sites. For the same reasons it can be observed that the variation of loss tangent of the prepared samples with Ni content has almost the same trend in inverse manner. From all these results, it can be concluded that doping of $\mathrm{Li}$ nanoferrites with $\mathrm{Ni}$ ions leads to improvement in their dielectrical properties especially in the sample at $x=0.6$ and these compositions make promising materials for microwave applications.

The variation of dielectric constant $\left(\varepsilon^{\prime}\right)$ and dielectric loss tangent $(\tan \delta)$ of prepared samples at $x=0.4$ with frequency at different temperatures has been investigated in Figure 7.

It is observed that dielectric constant $\left(\varepsilon^{\prime}\right)$ of prepared samples was decreased rapidly in the low frequency region and decrease is quite slow in the high frequency region; that is, dielectric constant is almost independent of frequency (shown in Figure 7(a)). This dielectric behaviour of ferrites was explained by Koops' theory [37]. According to this model, dielectric medium is assumed to be made up of highly conducting grains surrounded by nonconducting grain boundaries. The grain boundaries are more effective at low frequencies and grains are more effective at the higher frequencies. As the grain boundaries having the large resistance, the charge carriers (electrons) pile up there and produce large space charge polarisation which results in large value of dielectric constant at low frequency region. And further increasing the frequency, the charge carriers (electrons) change their direction of motion due to the fact that this accumulation of charge at the grain boundary decreases which results in the decrease of dielectric constant. From the figures it is also observed that dielectric constant values increase with increase in the temperature in the low frequency region because electron exchange between the $\mathrm{Fe}^{+2}$ and $\mathrm{Fe}^{+3}$ ions at octahedral sites was thermally activated. 


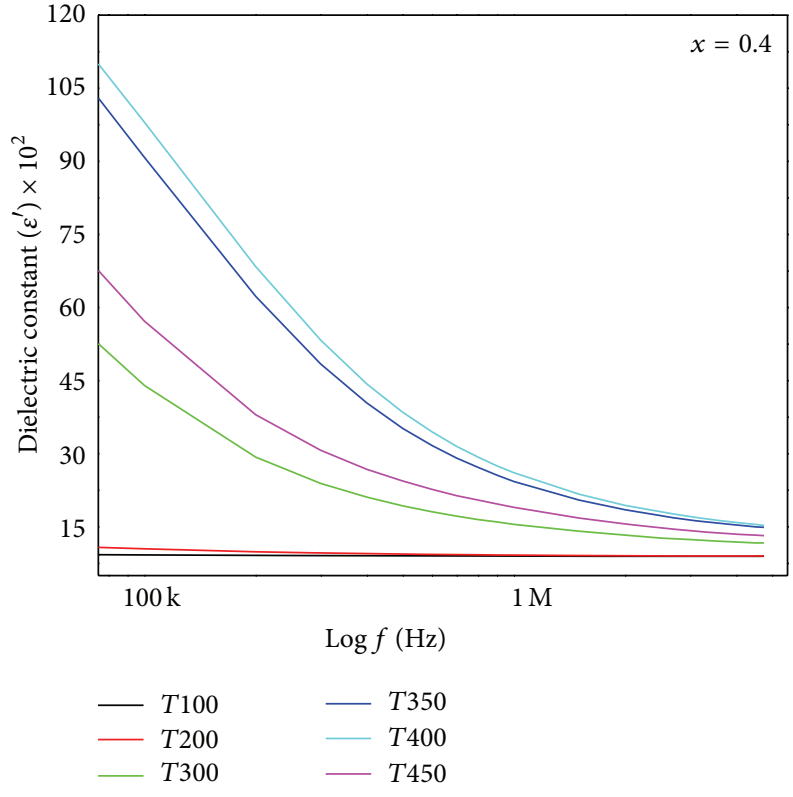

(a)

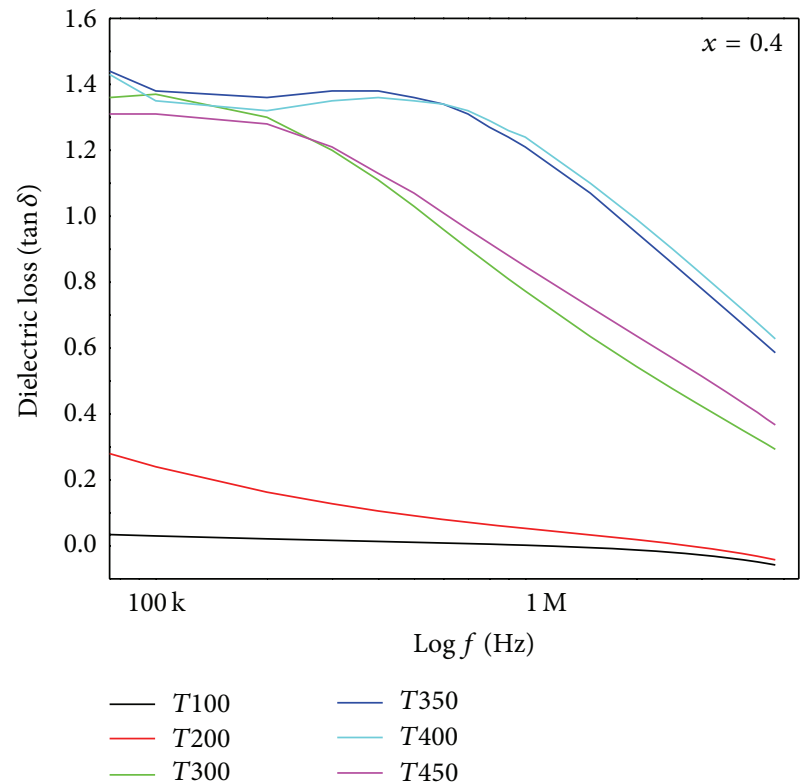

(b)

Figure 7: The variation of dielectric constant $\left(\varepsilon^{\prime}\right)$ and $(\tan \delta)$ with frequency at different temperatures of the Li-Ni ferrite system at $x=0.4$.

Figure 7(b) shows the variation dielectric loss tangent $(\tan \delta)$ with frequencies at different temperatures for $x=0.4$. It is observed that the dielectric loss decreases with frequency because the jumping frequency of charge carriers cannot follow the frequency of the applied field after certain frequency.

This figure also shows that the dielectric loss of the prepared samples increases with increasing the temperature because of the enhanced hopping of thermally energized electrons.

Figure 8 shows the variation of dielectric constant at $75 \mathrm{kHz}$ with temperature range $323 \mathrm{~K}-723 \mathrm{~K}$ for all ferrite samples. It can be observed that the dielectric constant of all the ferrite samples increases with increasing temperature up to certain temperature; after this temperature dielectric constant of the prepared samples is going to decrease; that temperature is known as dielectric transition temperature $T_{d}$ [38]. The decrease in the value of dielectric constant takes place when the jumping frequency of the electrons cannot follow the frequency of the applied electric field. From Figure 8 it is observed that dielectric transition temperature $T_{d}$ range is found to be in the $600 \mathrm{~K}-680 \mathrm{~K}$ for all prepared samples of $\mathrm{Li}_{0.5-0.5 x} \mathrm{Ni}_{x} \mathrm{Fe}_{2.5-0.5 x} \mathrm{O}_{4}$ system [39]. It is also observed that the slope variation in the Arrhenius plots (other than Curie point) was in the same temperature range only for all samples.

\section{Conclusions}

All the Li-Ni ferrites samples prepared by low temperature autocombustion method and single phase were confirmed through XRD analysis. The experimental results revealed that the lattice parameter, X-ray density of the prepared ferrite

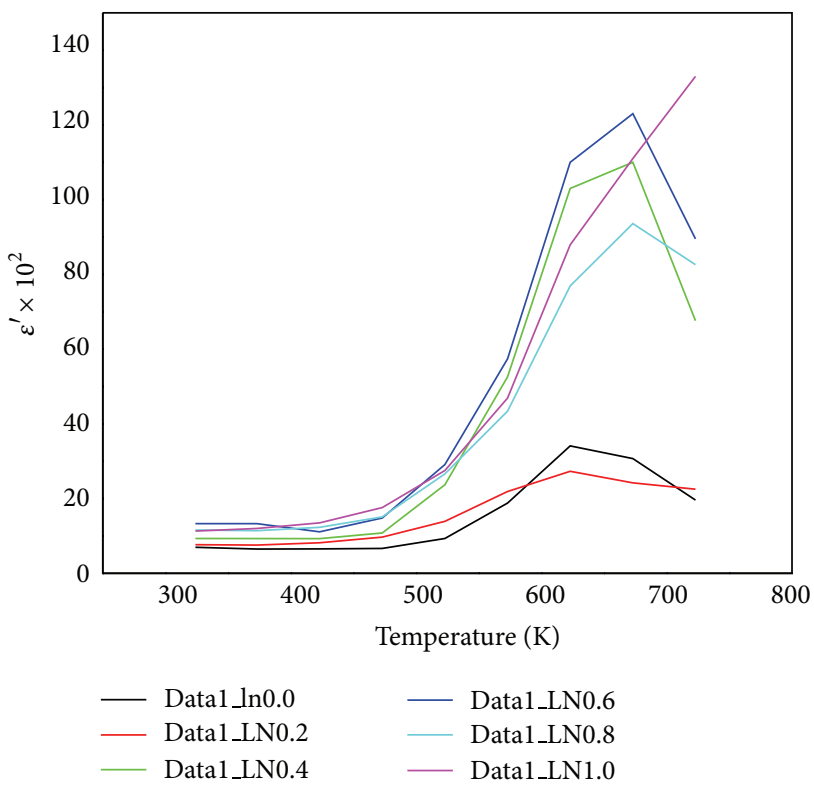

FIGURE 8: The variation of dielectric constant with temp. for $\mathrm{Li}_{0.5-0.5 x} \mathrm{Ni}_{x} \mathrm{Fe}_{2.5-0.5 x} \mathrm{O}_{4}$ nanoferrites.

samples, increases with increase in Ni-substituted concentration and the grain size is also in the nm range only. DC electrical resistivity of the prepared samples decreases with increasing in the temperature which shows the semiconducting behaviour of nanoferrites. It is observed that the discontinuity in the $\log (\sigma T)$ versus $1000 / T$ graph shows Curie point of the prepared ferrite samples. Curie temperature of 
the prepared $\mathrm{Li}-\mathrm{Ni}$ ferrites decreases with the increase of the Ni concentration. The variation of DC conductivity with temperature can be explained using the hopping mechanism of electrons between the $\mathrm{Fe}^{+2}$ and $\mathrm{Fe}^{+3}$. The dielectric constant of the prepared ferrite samples increases with increase in temperature up to certain temperature and afterwards decreases with increase in temperature.

\section{Conflict of Interests}

The authors declare that there is no conflict of interests regarding the publication of this paper.

\section{Acknowledgments}

The authors are very grateful to Professor K. Venu Gopal Reddy, Head, Department of Physics, University College of Science, Osmania University, Hyderabad. The authors are very thankful to UGC, New Delhi, for their financial assistance through Major Research Project (MRP).

\section{References}

[1] N. S. Gajbhiye and G. Balaji, "Mossbaur studies of nanosize $\mathrm{CuFe}_{2} \mathrm{O}_{4}$ ferrites," in Advances in Nanoscience and Nano Tech, A. Sharma, Ed., NISCAIR, 2003.

[2] S. A. Jadhav, "Magnetic properties of Zn-substituted $\mathrm{Li}-\mathrm{Cu}$ ferrites," Journal of Magnetism and Magnetic Materials, vol. 224, no. 2, pp. 167-172, 2001.

[3] M. F. Al-Hilli, S. Li, and K. S. Kassim, "Gadolinium substitution and sintering temperature dependent electronic properties of Li-Ni ferrite," Journal of Magnetism and Magnetic Materials, vol. 324, pp. 873-879, 2012.

[4] A. M. A. El Ata, M. K. El Nimr, S. M. Attia, D. El Kony, and A. H. Al-Hammadi, "Studies of AC electrical conductivity and initial magnetic permeability of rare-earth-substituted Li-Co ferrites," Journal of Magnetism and Magnetic Materials, vol. 297, no. 1, pp. 33-43, 2006.

[5] A. M. A. El Ata, S. M. Attia, D. El Kony, and A. H. Al-Hammadi, "Spectral, initial magnetic permeability and transport studies of $\mathrm{Li}_{0.5-0.5 x} \mathrm{Co}_{x} \mathrm{Fe}_{2.5-0.5 x} \mathrm{O}_{4}$ spinel ferrite," Journal of Magnetism and Magnetic Materials, vol. 295, no. 1, pp. 28-36, 2005.

[6] S. A. Jadhav, "Structural and magnetic properties of Zn substituted Li-Cu ferrites," Materials Chemistry and Physics, vol. 65, no. 1, pp. 120-123, 2000.

[7] H. Kawazoe and K. Ueda, "Transparent conducting oxides based on the spinel structure," Journal of the American Ceramic Society, vol. 82, no. 12, pp. 3330-3336, 1999.

[8] P. V. Reddy and T. S. Rao, "X-ray studies on lithium-nickel and manganese-magnesium mixed ferrites," Journal of the LessCommon Metals, vol. 75, no. 2, pp. 255-260, 1980.

[9] R. S. Devan, Y. D. Kolekar, and B. K. Chougule, "Transition metal-doped rare earth vanadates: a regenerable catalytic material for SOFC anodes," Journal of Physics: Condensed Matter, vol. 18, no. 43, pp. 9809-9821, 2006.

[10] M. A. Gabal and S. S. Ata-Allah, "Effect of diamagnetic substitution on the structural, electrical and magnetic properties of $\mathrm{CoFe}_{2} \mathrm{O}_{4}$," Materials Chemistry and Physics, vol. 85, no. 1, pp. 104-112, 2004.
[11] E. Veena Gopalan, I. A. Al-Omari, K. A. Malini et al., "Impact of zinc substitution on the structural and magnetic properties of chemically derived nanosized manganese zinc mixed ferrites," Journal of Magnetism and Magnetic Materials, vol. 321, no. 8, pp. 1092-1099, 2009.

[12] E. Veena Gopalan, K. A. Malini, S. Saravanan, D. Sakthi Kumar, Y. Yoshida, and M. R. Anantharaman, "Evidence for polaron conduction in nanostructured manganese ferrite," Journal of Physics D: Applied Physics, vol. 41, no. 18, Article ID 185005, 2008.

[13] M. Srivastava, S. Chaubey, and A. K. Ojha, "Investigation on size dependent structural and magnetic behavior of nickel ferrite nanoparticles prepared by sol-gel and hydrothermal methods," Materials Chemistry and Physics, vol. 118, no. 1, pp. 174-180, 2009.

[14] S. S. Bellad, R. B. Pujar, and B. K. Chougule, "Structural and magnetic properties of some mixed Li-Cd ferrites," Materials Chemistry and Physics, vol. 52, no. 2, pp. 166-169, 1998.

[15] D. Ravinder, "Dielectric behaviour of mixed lithium-zinc ferrites," Journal of Materials Science Letters, vol. 11, no. 22, pp. 1498-1500, 1992.

[16] Y. Purushotham, M. B. Reddy, P. Kishan, D. R. Sagar, and P. V. Reddy, "Electrical conductivity and thermopower studies of titanium-substituted lithium-magnesium ferrites," Materials Letters, vol. 17, no. 6, pp. 341-345, 1993.

[17] S. A. Mazen and T. A. Elmosalami, "Structural and elastic properties of Li-Ni ferrites," ISRN Condensed Matter Physics, vol. 2011, Article ID 820726, 9 pages, 2011.

[18] S. S. Bhatu, V. K. Lakhani, A. R. Tanna et al., "Effect of nickel substitution on structural, infrared and elastic properties of lithium ferrite," Indian Journal of Pure and Applied Physics, vol. 45, no. 7, pp. 596-608, 2007.

[19] L. Vijayan, R. Cheruku, G. Govindaraj, and S. Rajagopan, "Ion dynamics in combustion synthesized $\mathrm{Na}_{3} \mathrm{Cr}_{2}\left(\mathrm{PO}_{4}\right)_{3}$ crystallites," Materials Chemistry and Physics, vol. 125, no. 1-2, pp. 184190, 2011.

[20] R. Cheruku, L. Vijayan, and G. Govindaraj, "Electrical relaxation studies of solution combustion synthesized nanocrystalline $\mathrm{Li}_{2} \mathrm{NiZrO}_{4}$ material," Materials Science and Engineering B: Solid-State Materials for Advanced Technology, vol. 177, no. 11, pp. 771-779, 2012.

[21] L. C. Pathak, T. B. Singh, S. Das, A. K. Verma, and P. Ramachandrarao, "Effect of $\mathrm{pH}$ on the combustion synthesis of nanocrystalline alumina powder," Materials Letters, vol. 57, no. 2, pp. 380-385, 2002.

[22] J. Chandradass, M. Balasubramanian, and K. H. Kim, "Synthesis and characterization of $\mathrm{LaAlO}_{3}$ nanopowders by various fuels," Materials and Manufacturing Processes, vol. 25, no. 12, pp. 14491453, 2010.

[23] J. Jing, L. Liangchao, and X. Feng, "Structural analysis and magnetic properties of $\mathrm{Gd}$-doped Li-Ni ferrites prepared using rheological phase reaction method," Journal of Rare Earths, vol. 25, no. 1, pp. 79-83, 2007.

[24] R. G. Kharabe, R. S. Devan, C. M. Kanamadi, and B. K. Chougule, "Dielectric properties of mixed Li-Ni-Cd ferrites," Smart Materials and Structures, vol. 15, no. 2, pp. N36-N39, 2006.

[25] F. F. Y. Wang, Treatise on Material Science and Technology, vol. 2, Academic Press, New York, NY, USA, 1973.

[26] R. W. Cahn, Physical Mettaliurgy, vol. 1, North Holland, Amsterdam, The Netherlands, 1985. 
[27] S. B. Patil, R. P. Patil, and B. K. Chougale, "DC electrical and thermo electric power measurement studies of $\mathrm{Ni}-\mathrm{Mg}-\mathrm{Zn}-\mathrm{Co}$ ferrites," Journal of Magnetism and Magnetic Materials, vol. 335, pp. 109-113, 2013.

[28] M. A. El Hiti, "Studies of structural, electric and magnetic properties of some mixed ferrites," Journal of Magnetism and Magnetic Materials, vol. 136, p. 138, 1994.

[29] A. N. Patil, R. P. Mahajan, K. K. Patankar, A. K. Ghatake, and S. A. Patil, "Magnetic and Optical properties of conduction mechanism in Copper ferrites," Indian Journal of Pure and Applied Physics, vol. 38, article 651, 2000.

[30] E. J. W. Verwey and J. H. de Boer, "Cation arrangement in a few oxides with crystal structures of the spinel type," Recueil des Travaux Chimiques des Pays-Bas, vol. 55, no. 6, pp. 531-540, 1936.

[31] A. Verma, T. C. Goel, R. G. Mendiratta, and R. G. Gupta, "Highresistivity nickel-zinc ferrites by the citrate precursor method," Journal of Magnetism and Magnetic Materials, vol. 192, no. 2, pp. 271-276, 1999.

[32] W. D. Kingery, H. K. Bowen, and P. R. Uhlum, Introduction to Ceramics, Wiley, New York, NY, USA, 1975.

[33] L. L. Hench and J. K. West, Principles of Electronic Ceramics, John Wiley \& Sons, New York, NY, USA, 1990.

[34] S. A. Mazen and H. A. Dawoud, "Temperature and composition dependence of dielectric properties in Li-Cu ferrite," Materials Chemistry and Physics, vol. 82, no. 3, pp. 557-566, 2003.

[35] I. Soibam, S. Phanjoubam, H. B. Sharma, H. N. K. Sarma, R. Laishram, and C. Prakash, "Effects of Cobalt substitution on the dielectric properties of $\mathrm{Li}-\mathrm{Zn}$ ferrites," Solid State Communications, vol. 148, no. 9-10, pp. 399-402, 2008.

[36] S. T. Assar and H. F. Aboshiesha, "Structure and magnetic properties of Co-Ni-Li ferrites synthesized by citrate precursor method," Journal of Magnetism and Magnetic Materials, vol. 324, no. 22, pp. 3846-3852, 2012.

[37] C. G. Koops, "On the dispersion of resistivity and dielectric constant of some semiconductors at audiofrequencies," Physical Review, vol. 83, article 121, 1951.

[38] K. L. Yadav and R. N. P. Choudary, "Study of structural electrical and optical properties of lead free based ceramic system," Journal of Materials Science Letters, vol. 19, p. 61, 1994.

[39] V. Verma, V. Pandey, V. N. Shukla, S. Annapoorni, and R. K. Kotnala, "Remarkable influence on the dielectric and magnetic properties of lithium ferrite by Ti and Zn substitution," Solid State Communications, vol. 149, no. 39-40, pp. 1726-1730, 2009. 

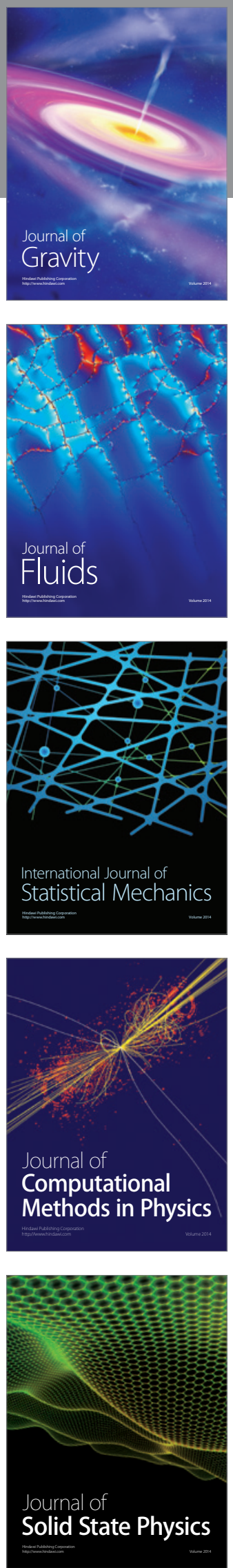

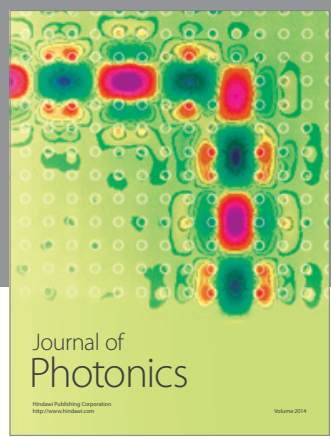

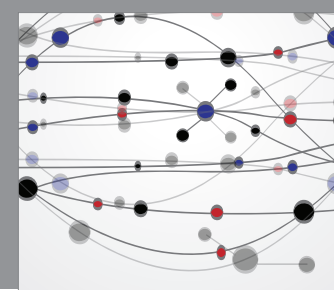

The Scientific World Journal

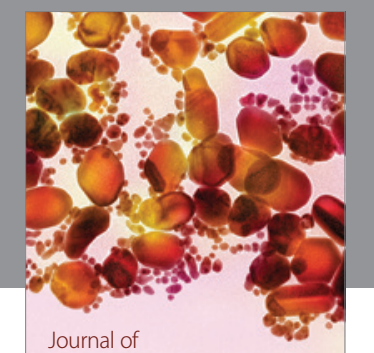

Soft Matter
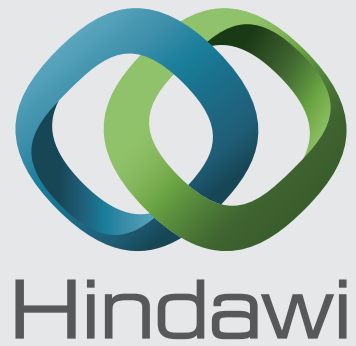

Submit your manuscripts at

http://www.hindawi.com
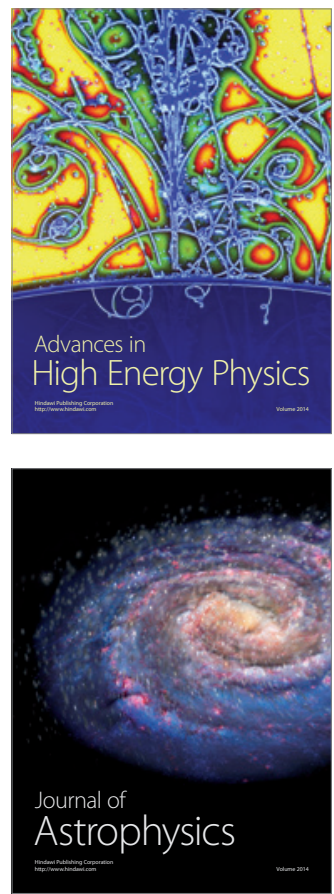
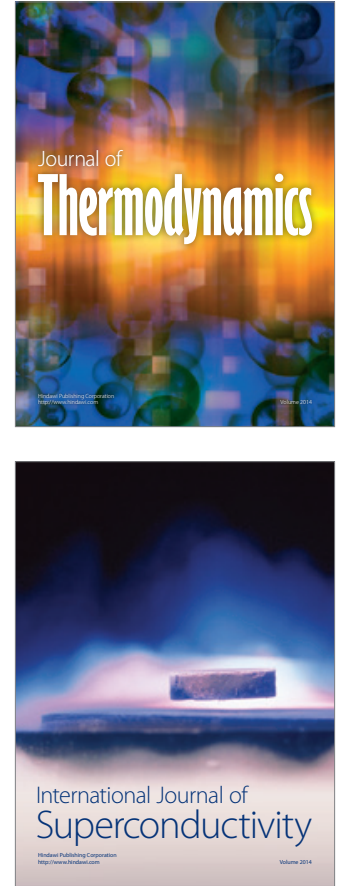
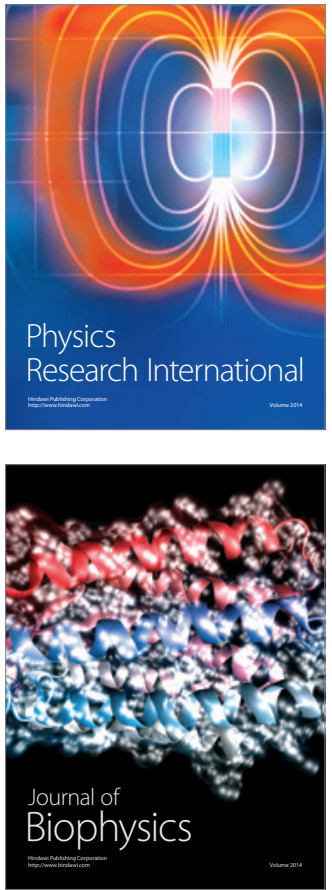
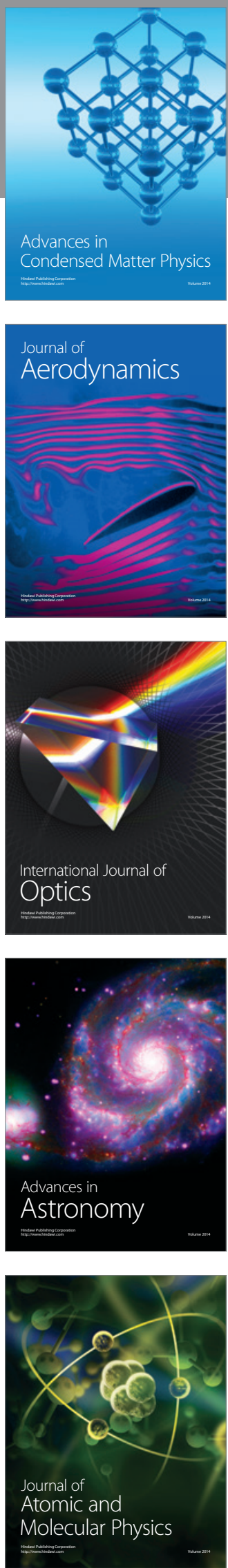